\title{
Seismic structure of the lithosphere and upper mantle beneath the ocean islands near mid-oceanic ridges
}

\author{
C. Haldar ${ }^{1}$, P. Kumar ${ }^{1}$, and M. Ravi Kumar ${ }^{1}$ \\ ${ }^{1}$ National Geophysical Research Institute (CSIR), Uppal Road, Hyderabad-500007, India \\ Correspondence to: P. Kumar (prakashk@ngri.res.in)
}

Received: 4 September 2013 - Published in Solid Earth Discuss.: 7 October 2013

Revised: 21 March 2014 - Accepted: 21 March 2014 - Published: 19 May 2014

\begin{abstract}
Deciphering the seismic character of the young lithosphere near mid-oceanic ridges (MORs) is a challenging endeavor. In this study, we determine the seismic structure of the oceanic plate near the MORs using the $P$-to- $S$ conversions isolated from quality data recorded at five broadband seismological stations situated on ocean islands in their vicinity. Estimates of the crustal and lithospheric thickness values from waveform inversion of the $P$-receiver function stacks at individual stations reveal that the Moho depth varies between $\sim 10 \pm 1 \mathrm{~km}$ and $\sim 20 \pm 1 \mathrm{~km}$ with the depths of the lithosphere-asthenosphere boundary (LAB) varying between $\sim 40 \pm 4$ and $\sim 65 \pm 7 \mathrm{~km}$. We found evidence for an additional low-velocity layer below the expected LAB depths at stations on Ascension, São Jorge and Easter islands. The layer probably relates to the presence of a hot spot corresponding to a magma chamber. Further, thinning of the upper mantle transition zone suggests a hotter mantle transition zone due to the possible presence of plumes in the mantle beneath the stations.
\end{abstract}

\section{Introduction}

Mid-oceanic ridges (MORs) are the largest sources of magma on the earth. Being the locus of new lithosphere generation and accretion to the existing ones, their study assumes importance in understanding the dynamics of plate tectonics. These linear features on the ocean floor control the rheology of oceanic lithosphere, ridge topography, the style of oceanic crustal accretion and also affect the earth's deeper discontinuities. Created at the mid-oceanic ridges, new oceanic lithosphere undergoes cooling and thickening as it subsequently spreads away and again plunges down- ward into the mantle along the trenches by the process of subduction. In a broader perspective, the thermal contraction of lithosphere created at the ridge also defines the shape of the mid-oceanic ridge (Parsons and Sclater, 1977). The lithosphere is the rigid outer shell, made up of the crust and the uppermost part of the mantle that floats over a lowerviscosity asthenosphere that is seismically characterized by a low-velocity zone. The first seismic observation of the asthenospheric low-velocity layer was reported by Gutenberg, at a depth range of $\sim 50-200 \mathrm{~km}$ (Gutenberg, 1959). Therefore, any velocity reduction in the uppermost mantle, similar to the one at the lithosphere-asthenosphere boundary (LAB), has been sometimes referred to as the Gutenberg (G) discontinuity (Revenaugh and Jordan, 1991), which may define the top of the low-velocity layer.

Most of the seismological knowledge of the oceanic plates, particularly near the ridges, comes from highresolution 3-D seismic tomography studies using active source data (Evangelidis et al., 2004). The results reveal fine layering within the crust in the volcanic edifices of Ascension. Seismic reflection/refraction studies have also been carried out near the ridges (Bjarnson and Menke, 1993; Evangelidis et al., 2004; Rodgers and Harben, 1999) in and around the Atlantic. All these studies reveal a highly variable crustal structure. Surface-wave dispersion studies first elucidated the nature of the oceanic plate and LAB (Kanamori and Press, 1970; Leeds, 1975; Zhang and Tanimoto, 1993; Nettles and Dziewonski, 2008). However, the depth resolution of surface-wave and body-wave tomography studies is limited to $>40 \mathrm{~km}$. Shear-wave anisotropy studies suggest horizontally connected melts that characterize the LAB near the MOR and cause radial anisotropy at these depths (Nowacki et al., 2012). Attempts to understand the structure of the oceanic 
plates have been made through a number of seismological studies at different locations beneath the Pacific Ocean (Gaherty, 1999; Tan and Helmberger, 2007; Kawakatsu, 2009; Kumar and Kawakatsu, 2011; Kumar et al,. 2012; Rychert and Shearer, 2011; Schmerr, 2012, etc.). Logistic problems and the extreme costs compared to land surveys impose severe constraints on obtaining similar information about the nature of other MORs. Another factor which hampers bodywave observations from the oceanic data is the water reverberations that mostly contaminate the vertical components of the seismograms of the ocean bottom seismometers (Kumar et al., 2012). In this study, we attempt to investigate the seismic structure using the available data from five seismological stations situated on the islands located close to the mid-oceanic ridges. Although the crustal structure may not truly represent the nature of the oceanic plate due to possible influence of the islands, the deeper structure is devoid of such effects.

\section{Data and methods}

We used all the available teleseismic data recorded at stations located on five oceanic islands near MORs. The locations of the stations are shown in Fig. 1, together with the major plate boundaries and mid-oceanic ridges. In the present study, we use converted wave techniques, namely $P$-receiver functions (PRFs) (Burdick and Langston, 1977; Langston, 1977; Vinnik, 1977). Receiver functions are time series, computed from three component seismograms, which show the relative response of the earth structure near the receiver. The events with magnitude $\geq 5.5 \mathrm{Mb}$ in the epicentral distance range of $30-90^{\circ}$ are selected from all available back azimuths. We visually picked the waveforms having clear $P$ waves in the vertical component for further analysis. First, the $\mathrm{Z}, \mathrm{N}$ and $\mathrm{E}$ components are rotated into $\mathrm{Z}$ (vertical), $\mathrm{R}$ (radial), and $\mathrm{T}$ (transverse) system using back azimuths derived from the waveforms. We further rotate the ZRT components into the LQT system using the theoretical angle of incidence determined by the global velocity model IASP91 and also with the angle of maximum polarization direction of $P$-wave. We chose only those events whose differences in theoretical and waveform back-azimuth and incidence angle are less than $30^{\circ}$ and $5^{\circ}$, respectively. Further, we derive the $P$-receiver functions in time domain by deconvolving the radial components by their respective vertical ones. The deconvolution makes the equalization of source and propagation path effects. All of the above steps involved in computation of $P$-receiver functions are performed using the codes written in Seismic Handler (http://www.seismic-handler.org, K. Stammler, 1992), a seismological analysis tool. The $P$ receiver functions thus obtained are then moveout corrected to a reference slowness of $6.4 \mathrm{~s} /{ }^{\circ}$ (Yuan, 1997) in order to remove the dependence of the travel times of the converted phases on the source receiver distance. In addition, we stack several $P$-receiver functions after moveout correction, to enhance the signal to noise ratio.

\section{Modeling of receiver functions}

At each of the stations, the stacked receiver function traces along with the 2 sigma error limits, computed utilizing the bootstrap resampling technique, are shown in Fig. 2. In this bootstrap analysis, a single receiver function stack is generated by summation of those traces indicated by a random number generator where the number of traces for summation remains the same as the total number of $P$-receiver functions at a given station. This procedure is repeated 500 times, by stacking a totally different sequence of traces corresponding to randomly generated trace numbers. The mean and standard deviations of the amplitudes from 500 realizations at each point on the time axis are then calculated. In Fig. 2, we marked the prominent phases, namely Moho, LAB and another low-velocity layer (L). All these phases have their amplitudes above the 2 sigma error limit. Although the positive conversions from the Moho and a negative one from the $\mathrm{LAB}$ are prominent in this figure, the multiples from either of these are not obvious. This could be because of to their annihilation due to interference from other phases.

In order to constrain the seismic structure of the lithosphere, the stacks of the moveout-corrected traces at each station are inverted using a linearized time domain iterative waveform inversion scheme (Ammon et al., 1990), where for each model, the synthetic seismograms for the slowness corresponding to the stacked trace are computed using the reflectivity method (Fuchs and Müller, 1971; Kind, 1978). We allowed the generation of all primary and multiple phases. The synthetic traces are rotated and deconvolved in the same manner as the observed traces, for a meaningful comparison.

The receiver function results are summarized in Table 1 and the stacked traces observed are shown in Fig. 2. Since the islands are volcanic in nature, the velocities and crustal thickness values from other studies are used as constraints in the inversion. While modeling the $P$-receiver functions at various stations, the velocity of the basaltic layer was adopted from the available published values (Rodgers and Harben,1999; Christensen, 1973). Also, the velocities in the crustal part are kept close to the estimates obtained regionally and globally from active seismic experiments (Shinohara, 2008; White, 1992), except for the station ROSA, where the data required a top layer to have very low shear velocity, probably due to the presence of sediments near the surface.

The piercing points of the $P$-to- $S$ conversions at a depth of $100 \mathrm{~km}$, plotted in the inset maps for each station in Fig. 1, reveal a maximum offset of $0.5^{\circ}$. Since we model the stacked traces, any lateral heterogeneity within $0.5^{\circ}$ is averaged. Figure 3 shows the corresponding L-components of our stack traces, which essentially contain only the $P$-waves as first arrivals. Figure 4 shows the velocity models obtained at each 


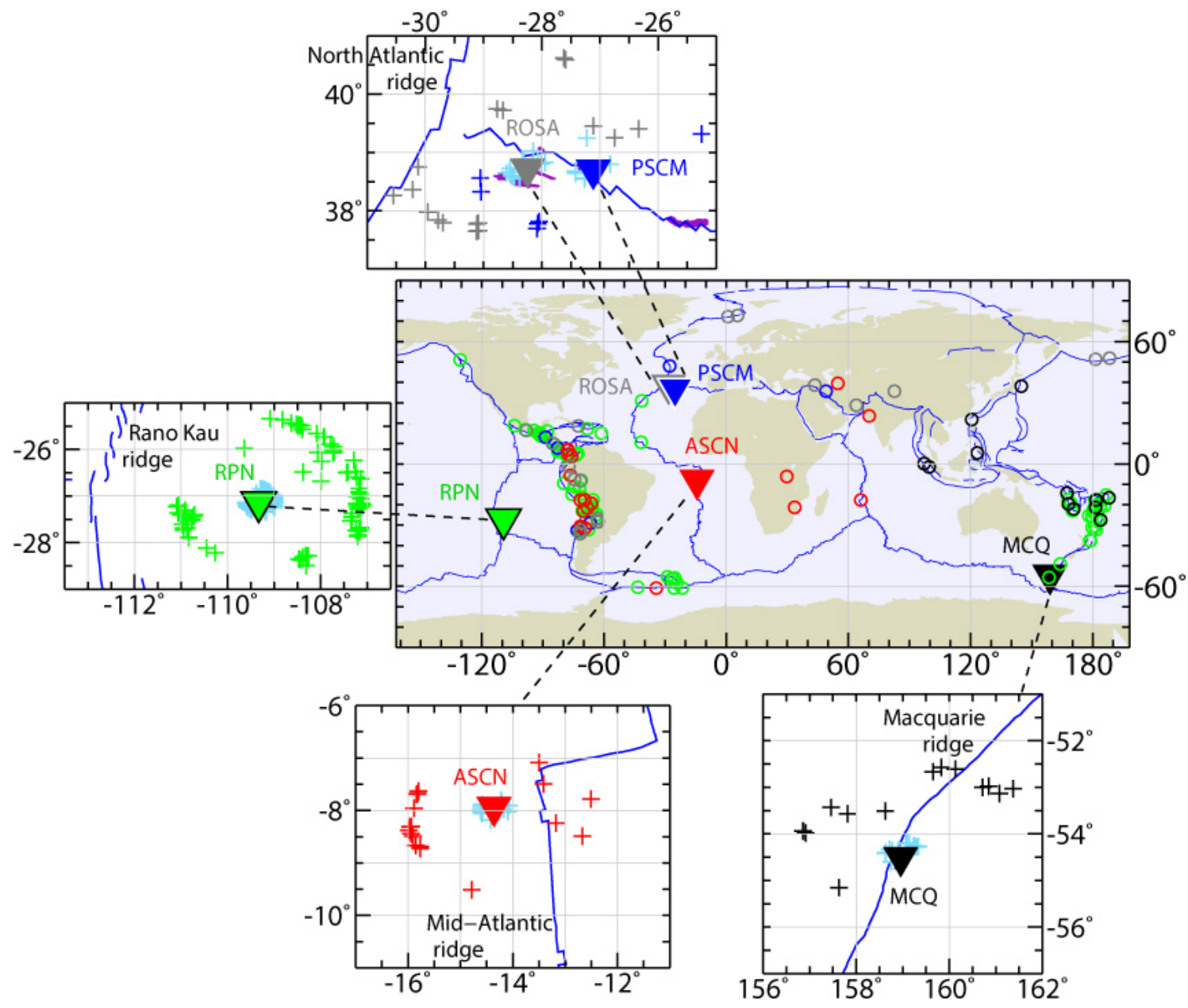

Figure 1. Location of the seismic stations (inverted triangles) used in the present study. Mid-oceanic ridge (MOR) boundaries are also shown (blue lines) with their names in the inset maps. The color code of the stations corresponds to the colors of the lines in Figs. 2 and 4 . Open circles indicate the geographical distribution of the events corresponding to the stations of the same color. Insets corresponding to each station show their relative position with respect to the mid-oceanic ridges. The crosses in the insets are the $P$-to- $S$ conversion points corresponding to the depths at $100 \mathrm{~km}$ (cyan, nearest to the station) and at $520 \mathrm{~km}$ (same color as the corresponding station, farther away).

station from inversion, together with the waveform matching of the observed and synthetic traces. Apart from the Moho and $\mathrm{LAB}$, the models reveal additional low-velocity layers (L) in the sub-lithospheric mantle below the three stations RPN, ROSA and ASCN.

\section{Results and discussions}

\subsection{Mid-Atlantic Ridge (PSCM, ROSA and ASCN)}

Our modeling results indicate that the crust-mantle boundary is located at depths of $\sim 12 \pm 1,16 \pm 1$ and $10 \pm 1 \mathrm{~km}$ for ROSA, PSCM and ASCN respectively. Both the stations PSCM (in Terceira) and ROSA (in São Jorge), in the middle of the North Atlantic Ocean (see Fig. 1), are volcanic in origin and about $10 \mathrm{~km}$ away from the MOR, making them some of the closest landmasses to an active, oceanic spreading cen- ter. ASCN is located in the South Atlantic Ocean on Ascension, a volcanic island located $100 \mathrm{~km}$ west of the MOR.

Near the station ASCN, wide-angle reflection seismic tomography studies indicate the Moho at a depth of $\sim 10.2 \mathrm{~km}$ (Evangelidis et al., 2004). The depth to the LAB (see Table 1) beneath the stations PSCM, ROSA and ASCN is $65 \pm 4$, $40 \pm 7$ and $50 \pm 4 \mathrm{~km}$, respectively. Here we define the LAB as the depth corresponding to the middle part of the velocity decrease below the Moho (see Fig. 4). The result for the station ASCN is consistent with observations by $\mathrm{Li}$, et al. (2003). The depths of the LAB beneath stations ROSA $(\sim 40 \pm 4 \mathrm{~km})$ and PSCM $(\sim 65 \pm 7 \mathrm{~km})$ are quite different, although they are separated by only $\sim 100 \mathrm{~km}$. The older crust (19 My) at PSCM shows a larger plate thickness compared to a younger crust (13 My) at ROSA (http://www.ngdc. noaa.gov/mgg/ocean_age/data/2008/grids/age/). The inset of Fig. 1 shows that station PSCM is located on Terceira, which 
Table 1. The Moho, LAB and LVL depths beneath the stations used in this study, together with the $P$-to- $S$ conversion times from the upper mantle discontinuities.

\begin{tabular}{|c|c|c|c|c|c|c|c|c|c|c|c|c|}
\hline Station & Region & $\begin{array}{l}\text { No. of } \\
\text { traces }\end{array}$ & Lat & Lon & Period & $\begin{array}{l}\text { Elv } \\
(m)\end{array}$ & $\begin{array}{l}\text { Moho } \\
(\mathrm{km})\end{array}$ & $\begin{array}{l}\text { LAB } \\
(\mathrm{km})\end{array}$ & $\begin{array}{l}\mathrm{L} \\
(\mathrm{km})\end{array}$ & $410(\mathrm{~s})$ & $660(\mathrm{~s})$ & $\begin{array}{l}\text { Age } \\
\text { (Ma) }\end{array}$ \\
\hline ASCN & $\begin{array}{l}\text { Ascension, } \\
\text { Atlantic Ocean }\end{array}$ & 20 & -7.93 & -14.36 & $\begin{array}{l}1994- \\
2010\end{array}$ & 173 & $10 \pm 1$ & $50 \pm 4$ & $75 \pm 4$ & $\begin{array}{l}46.0 \\
\pm 0.2\end{array}$ & $\begin{array}{l}68.4 \\
\pm 0.3\end{array}$ & 5 \\
\hline $\begin{array}{l}\text { MCQ1 } \\
\text { MCQ2 }\end{array}$ & $\begin{array}{l}\text { Macquarie Island, } \\
\text { Pacific Ocean }\end{array}$ & 8 & -54.49 & 158.95 & $\begin{array}{l}2005- \\
2012\end{array}$ & 14 & $19 \pm 1$ & $42 \pm 2$ & - & $\begin{array}{l}48.6 \\
\pm 0.3 \\
46.8 \\
\pm 0.2\end{array}$ & $\begin{array}{l}70.6 \\
\pm 0.3 \\
-\end{array}$ & 3 \\
\hline PSCM & $\begin{array}{l}\text { Terceira, } \\
\text { Atlantic Ocean }\end{array}$ & 7 & 38.70 & -27.11 & $\begin{array}{l}2000- \\
2002\end{array}$ & 400 & $16 \pm 1$ & $65 \pm 7$ & - & $\begin{array}{l}47.8 \\
\pm 0.3\end{array}$ & $\begin{array}{l}71.6 \\
\pm 0.2\end{array}$ & 19 \\
\hline ROSA & $\begin{array}{l}\text { São Jorge, } \\
\text { Atlantic Ocean }\end{array}$ & 18 & 38.72 & -28.24 & $\begin{array}{l}2008- \\
2012\end{array}$ & 310 & $12 \pm 1$ & $40 \pm 4$ & $106 \pm 4$ & $\begin{array}{l}46.8 \\
\pm 0.3\end{array}$ & $\begin{array}{l}70.6 \\
\pm 0.3\end{array}$ & 13 \\
\hline RPN1 & $\begin{array}{l}\text { Easter Island, } \\
\text { Pacific Ocean }\end{array}$ & 29 & -27.12 & -109.33 & $\begin{array}{l}1988- \\
2012\end{array}$ & 110 & $12 \pm 1$ & $46 \pm 2$ & $75 \pm 2$ & $\begin{array}{l}45.2 \\
\pm 0.3\end{array}$ & - & 6 \\
\hline RPN2 & & 58 & & & & & & & & $\begin{array}{l}46.8 \\
\pm 0.3\end{array}$ & $\begin{array}{l}69.4 \\
\pm 0.3\end{array}$ & \\
\hline
\end{tabular}

\pm indicates the $\pm 2 \mathrm{SE}$ in these values.

is much further from the main north Mid-Atlantic Ridge compared to ROSA. These two stations are situated on a complex triple junction. The possible reason for this discrepancy might be due to the influence of the compositional nature of the oceanic islands and structural complexity as evident from the surface bathymetry.

\subsection{Rano Kau Ridge (RPN) and Macquarie Ridge (MCQ)}

Station RPN is situated on Easter Island $\sim 350 \mathrm{~km}$ east from the Rano Kau Ridge in the Pacific, while station MCQ is located on Macquarie Island, which lies in the middle of the Macquarie Ridge (Duncan et al., 1998; Tapley et al., 2004). Both these volcanic islands are dominated by the presence of basalt and gabbro (Duncan and Varne, 1988; Jorg, 2005). The results of receiver function modeling (Fig. 5) suggest a crustal thickness of $\sim 12 \pm 1 \mathrm{~km}$ and a plate thickness of $46 \pm 2 \mathrm{~km}$ at station RPN. On the other hand, the crust is much thicker $(\sim 19 \pm 1 \mathrm{~km})$ below the station MCQ and the observation of LAB is dubious. The negative phases seen close to $6 \mathrm{~s}$ and $10 \mathrm{~s}$ are barely above the error limit (Fig. 2). Station MCQ is directly located on the MOR, but the retrieved Moho depth is larger than expected. This might be due to the fact that the observations are more representative of the islands. The LAB depth found below RPN is consistent with the results obtained earlier from $S$ receiver functions (Heit et al., 2007; Li, et al., 2003). This study suggests that the numerical value corresponding to the negative discontinuity below RPN might correspond to an oceanic LAB.

\subsection{Shear-wave velocity drop across LAB}

There are a number of models that describe the generation and migration of melt in a ridge system (Spiegelman and McKenzie, 1987; Phipps-Morgan, 1987; Sparks and Parmentier, 1993; Garmany, 1989; Buck and Su, 1989; Kelemem et al., 1997, etc.). However, geophysical studies, which help in constraining the existing models, are quite limited. The most important geophysical study aimed at deciphering the melt generation was the MELT experiment (Forsyth, 1992). Results from inversion of Love wave dispersion data from the East Pacific Rise revealed an asymmetric velocity structure across the ridge (Dunn and Forsyth, 2003), where a crustal magma chamber is confined.

Our modeling results suggest variable shear-wave velocity contrasts across the LAB for the five stations on the oceanic islands close to the mid-oceanic ridges. The inversion results reveal that the first-order discontinuities are not characterized by an abrupt change in shear velocity. The need for incorporating a gradational nature of the velocity interfaces in order to fit the observed and computed waveforms is due to lack of multiples. The velocity contrast across the LAB varies from $\sim 10 \pm 4 \%$ to $\sim 12 \pm 3 \%$, except for station ROSA, where an abnormal reduction of $22 \%$ is observed. This value may not be so reliable in view of the large error associated with the value $(22 \pm 9 \%)$. Hence, in the present discussion we will not take into account the velocity jump for the station ROSA. Here, we estimated the velocity contrast by taking the average lid velocity and minimum asthenospheric shear velocity. Also, the drop across LAB is sharp in nature, implying the presence of partial melt in the asthenosphere (Holtzman and Kohlsedt, 2007; Mierdel et al., 2007; Kawakatsu et al., 2009). The alteration of seismic velocities or attenuation is often used to interpret the amount and spatial disposition 


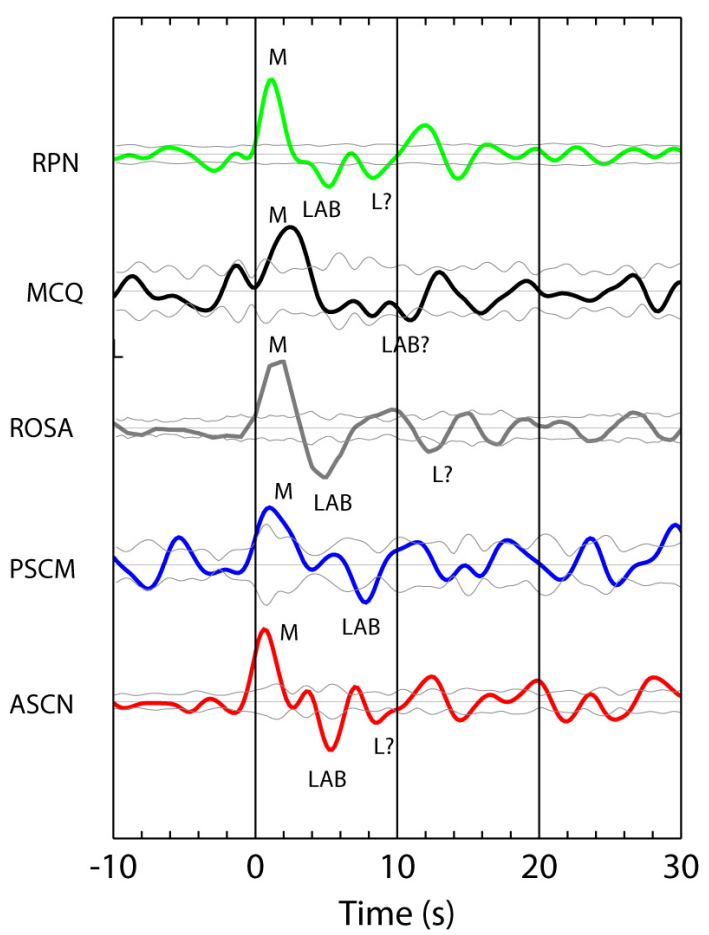

Figure 2. Observed $P$-receiver function stacks (solid lines) at the five stations. Before stacking, the receiver functions are low-pass filtered with a corner frequency of $3 \mathrm{~s}$ and moveout corrected to a reference slowness of $6.4 \mathrm{~s} /{ }^{\circ}$ using the IASP91 Earth model. The two gray lines on both sides of the mean lines represent the $2 \sigma$ standard error estimated using bootstrap resampling technique. The color codes correspond to different stations: Black, MCQ; Red, ASCN; Blue, PSCM; Green, RPN and Grey, ROSA. Different discontinuities are marked as M, Moho; LAB, lithosphere-asthenosphere boundary and L. sub-lithospheric low-velocity layer.

of partial melts in the uppermost mantle (i.e., Humphreys and Dueker, 1994; Zhao et al., 1992; Sobolev et al., 1996; Xu and Wiens, 1997; Dunn and Toomey, 1997; Kawakatsu et al., 2009). The sharp and abrupt drop in shear-wave velocity can be reconciled by the fact that the hot mantle upwelling near the ridges possibly enhances the reflectivity of the LAB (Schmerr, 2012). Moreover, the fraction of melt retention in the asthenosphere may cause such a large drop in shear velocity. Inclusion of little more than $1 \%$ melt in the asthenosphere, in addition to the temperature contrast, provides a realistic explanation of this velocity drop (Hammond and Humphreys, 2000; Rychert et al., 2012). Karato (1990) indicated that the presence of $\mathrm{H}_{2} \mathrm{O}$ in olivine weakens the material. Recently, Karato (2013) argued against the various partial melt models to explain the seismically observed anomalies and emphasized the important role played by the geometry of melt. However, the presence of hydrogen in the uppermost mantle may present an alternate model (Dai and Karato, 2009). Anelastic relaxation caused by the elastically accommodated grain-boundary sliding may also be a cause

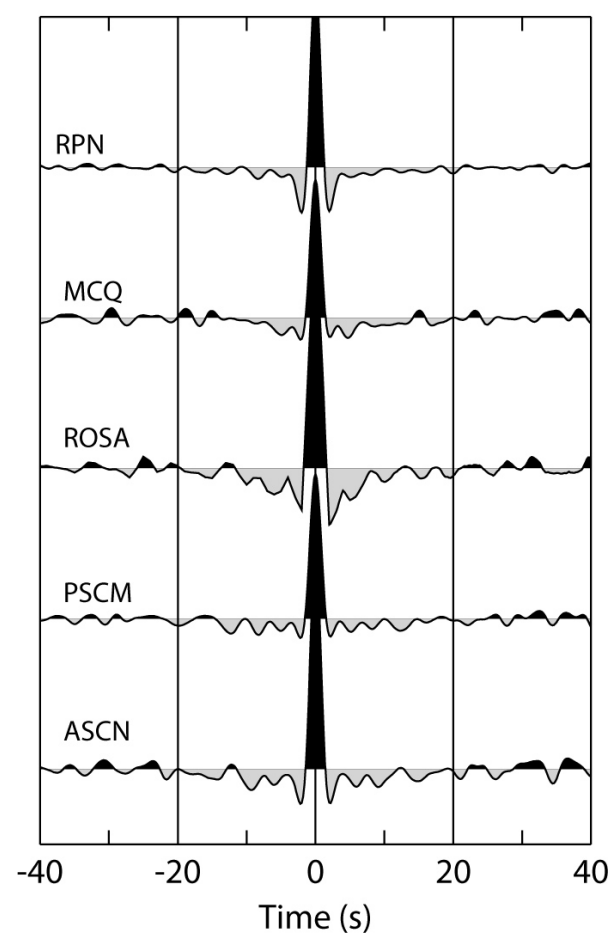

Figure 3. Stacked L-component receiver functions at different stations that essentially indicate the $P$-wave at zero time.

of large velocity drops of more than $5 \%$ (Karato, 2012). In the normal oceanic (not ocean island) plate, there is an indication of an abrupt increase in electrical conductivity (Shankland and Waff, 1977; Honkura, 1975; Utada and Baba, 2013), often interpreted as the electrical asthenosphere, favoring the idea of partial melts. Interestingly this layer corresponds to the seismologically identified layer.

Figure 6 illustrates the variation of plate thickness with age. It is clearly seen that the seismologically estimated lithospheric thicknesses in oceanic environment generally show an asymptotic increase with age, in agreement with the thermally predicted models (e.g., Stein and Stein, 1992; Kawakatsu et al., 2009). The presence of a significant scatter in the data requires incorporation of additional controlling factors. The present values obtained from the receiver function analysis (Table 1) seem to fill the existing gap in the lower end of the age spectrum and are consistent with the already observed values using the receiver function analysis.

\section{Sub-lithospheric low-velocity layer}

The observed $P$-receiver function traces (Figs. 2, 4 and 5) show an additional negative phase for stations RPN, ROSA and ASCN. We interpret the shallower LVLs as conversions from the LAB, since they are consistent with previous receiver function studies (Li et al., 2003; Heit et al., 2007; Rychert and Shearer, 2009 etc.). These values are close to 

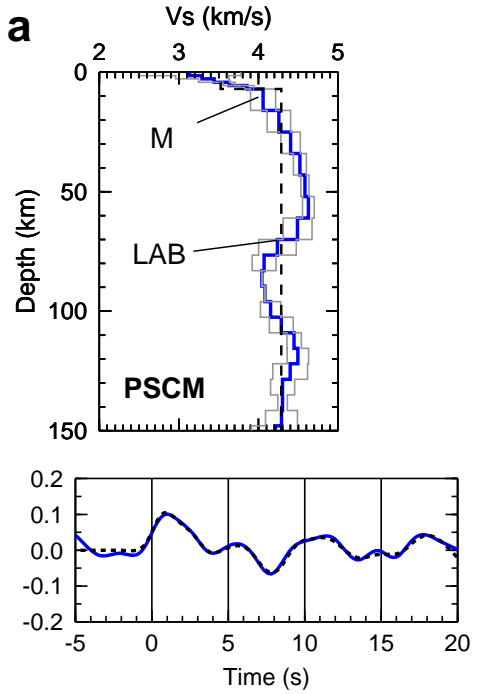
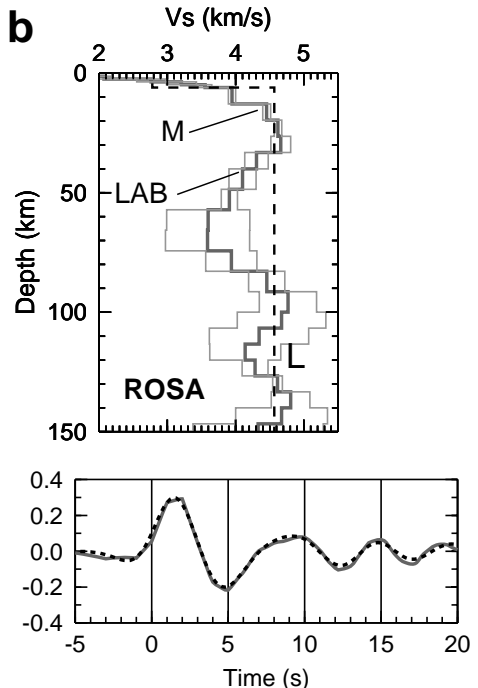
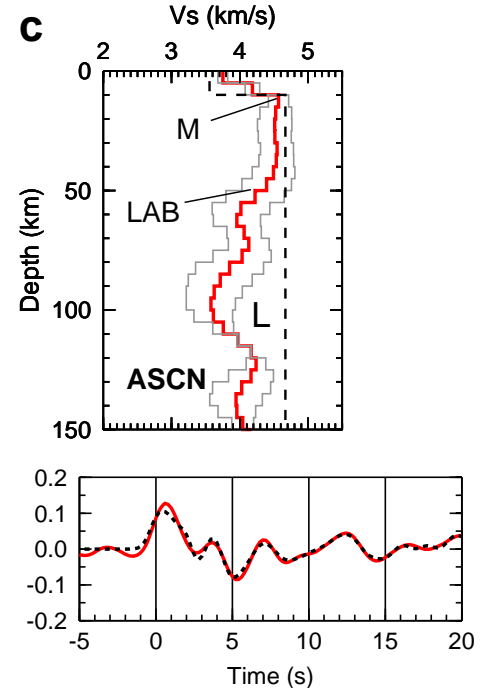

Figure 4. Models obtained by inversion of stacked traces in the bottom panel (colored as in Fig. 1) of each subplot. Synthetic traces (black dashed lines) computed from these models fit the observed traces well for the stations PSCM, ROSA and ASCN. The two gray lines that bound the thick colored lines model in the upper panel of each subplot are the $\pm 2 \mathrm{SE}$ in the velocity models derived from inversion. The dashed black line shows the 1-D starting velocity model used to invert the data.
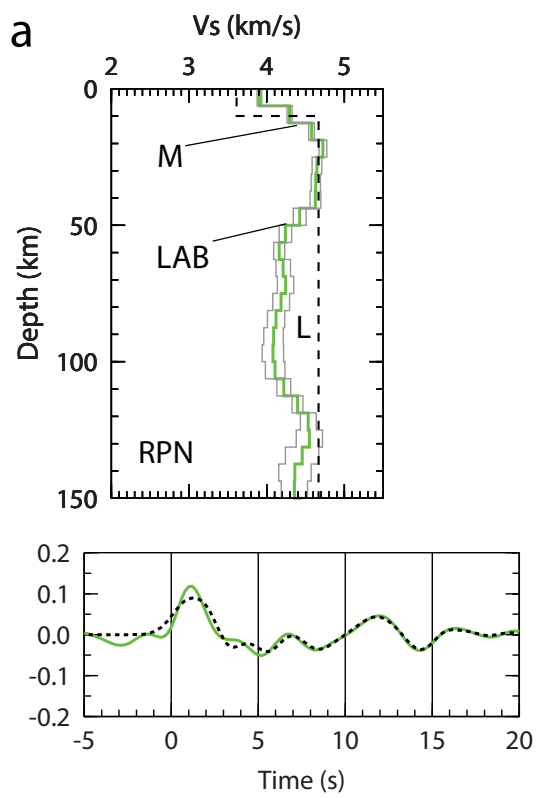

Figure 5. Same as Fig. 4 for the stations RPN and MCQ.

those predicted by the cooling model for the ocean lithosphere. The converted phases related to the deeper lowvelocity layers (Fig. 2) below RPN, ROSA and ASCN are observed much beyond the error limits. Owing to the proximity of these stations to the mid-oceanic ridges, the possible source for the generation of these LVLs may be related to the source of magma at a depth range of $\sim 75-106 \mathrm{~km}$, from where the magma ascends along narrow lithospheric openings. For the region close to the ridges, occurrence of hori-
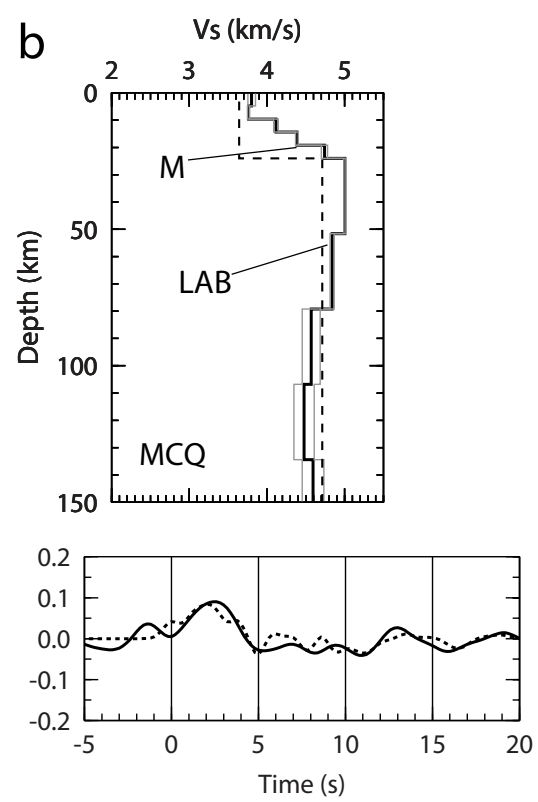

zontal layers of connected melt pockets has been proposed based on the nature of shear-wave anisotropy (Nowacki et al, 2012). The mid-oceanic ridges receive magma from the plume that feeds the hot magma from below. The most volatile magmas reside at deeper depths. For example, Ascension is supposed to be a product of flow from an off-axis plume to the spreading axis (Brozena, 1986). These locations are where the MORs interact with the mantle plume (Montagner and Ritsema, 2001) and possibly produce the second 


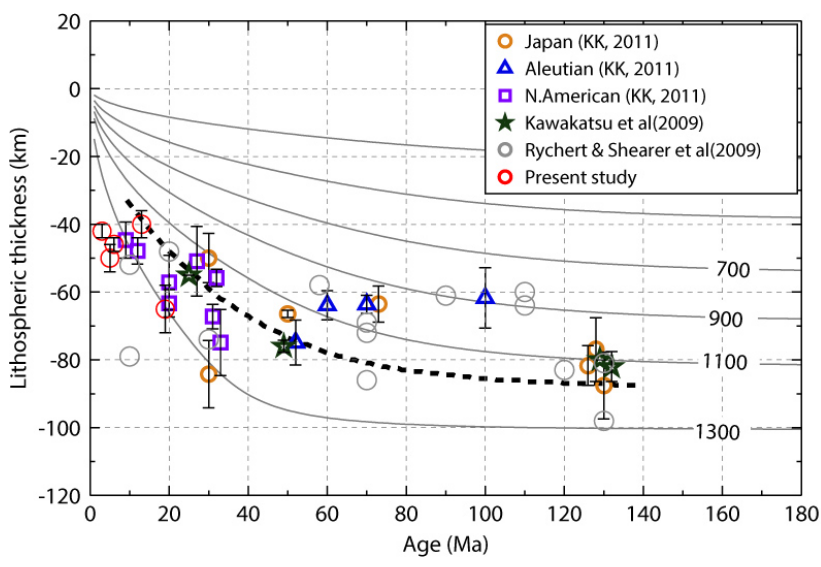

Figure 6. Observed lithospheric thickness values plotted against their age. Different color symbols denote data from different sources and red open circles denote the observations from the present study. Isotherms (gray contour lines with a $200^{\circ} \mathrm{C}$ interval) and the estimated top of partial melting region (the black, dashed contour line) are taken from Kawakatsu et al. (2009). KK: Kumar and Kawakatsu et al. (2011).

low-velocity layers (L), as observed along the Mid-Atlantic Ridge, where regions affected by the shallow mantle plumes are detected.

An interesting review by Sinton and Detrick (1992) presented geophysical and petrological evidence for the distribution and behavior of magma bodies beneath the ridges. When these magma bodies assume a crystalline form greater than about $50 \%$, rheologically they behave much like a solid. The presence of melts in the lower crust and also in the upper mantle is suggested by active source tomography (Toomey et al., 1990; Dunn and Toomey, 1997) and compliance techniques (Crawford et al., 1991; Crawford et al., 1998; Crawford and Webb, 2002). In the latter technique, the pressure field caused by the long-period ocean waves that deform the sea floor is studied. The relation between pressure and deformation is called compliance and used to investigate the structure under MOR locations.

\section{Upper mantle discontinuities}

Figure 7 shows the $P$-receiver function stacks at individual stations after the application of a low-pass filter with a corner frequency of $6 \mathrm{~s}$ in the time domain. The stacks clearly reveal the global upper mantle seismic discontinuities typically detected at 44.1 and $68.1 \mathrm{~s}$. The lateral extent of the $P$-to- $S$ conversion points at a depth of $520 \mathrm{~km}$ (insets in Fig. 1) suggests that they sample regions far away from the ridges. Stacked traces, in fact, represent an average character of the upper mantle below the station. Due to the large sampling of upper mantle $P$-to- $S$ conversions, we grouped the traces in such a way that one group is far from the ridge and other nearer to it. Station RPN (in Fig. 7) has two groups labeled as RPN1 and RPN2. Similarly, we made two clusters for MCQ. Other stations like ASCN, ROSA and PSCM have only one cluster, since the other clusters had much fewer traces. The $P$-to$S$ conversion times from the 410 and $660 \mathrm{~km}$ discontinuities with their errors are depicted in Table 1 . The oceanic stations reveal a delay in both the phases (see Table 1). These seismic discontinuities are globally observed and generally interpreted to be formed due to a phase transformation in the mantle from olivine to spinel and from spinel-structured gamma phase to perovskite-structured magnesiowüstite (Duffy and Anderson, 1989) respectively. These phases are in a state of equilibrium governed by the temperature and pressure at those depths, described by the Clapeyron slope. The Clapeyron slope is positive and negative for the 410 and $660 \mathrm{~km}$ discontinuities respectively (e.g., Bina and Helffrich, 1994). Thus, the respective locations of these phases can be interpreted in terms of the temperature in the upper mantle. For temperatures in excess of $\sim 200^{\circ} \mathrm{C}$, the separation between these discontinuities can be reduced by $\sim 20-30 \mathrm{~km}$ (Helffrich, 2000). The $P$-to- $S$ conversion times of the upper mantle discontinuities also depend on the average shear velocity in the upper mantle, implying that any discrepancies in these timings are related to the velocity perturbation in the uppermost mantle. The delays in both the phases might also indicate the lower average velocity in the upper mantle implying a thinner mantle lid and/or higher temperature of the oceanic lithosphere as compared to the continental mantle, corroborated by the LAB at shallower depths.

In the present study, the conversion times from the $410 \mathrm{~km}$ global discontinuity vary from 46 to $48.6 \mathrm{~s}$, while those from the $660 \mathrm{~km}$ discontinuity range between $68.4 \mathrm{~s}$ and $71.6 \mathrm{~s}$. All the stations show a delay in both the discontinuities with respect to the global average values predicted by the IASP91 model. These observed delays might be related to elevated upper-mantle temperatures just below the mid-oceanic ridges where hot magmas continuously pour out to make new lithosphere. These values are in general agreement with the earlier results in oceanic environments obtained from receiver function analysis ( $\mathrm{Li}$ et al., 2003) and SS precursors (Gu and Dziewonski, 2002). The observed values suggest that the thickness of the upper mantle transition zone varies between $22 \mathrm{~s}(\sim 220 \mathrm{~km})$ and $24 \mathrm{~s}(\sim 240 \mathrm{~km})$ compared to the global average value of $24 \mathrm{~s}(\sim 240 \mathrm{~km})$. This thinning of the transition zone favors a hotter mantle (e.g., Agee, 1997; Shearer, 2000; Deuss, 2007). For the station ASCN, the transition zone is $\sim 16 \mathrm{~km}(1.6 \mathrm{~s})$ thinner on the western side of the ridge compared to the global average value (Fig. 7). For the eastern side, we do not have enough data to arrive at a conclusive result. For the station MCQ, the transition zone on the western side of ridge is $\sim 20 \mathrm{~km}$ thinner $(2 \mathrm{~s})$. For stations PSCM and ROSA, our conversion point plots show that the data sample a similar upper mantle region (Fig. 7) and the upper mantle transition zone (within the error limits) is normal compared to the global average value. On the other 

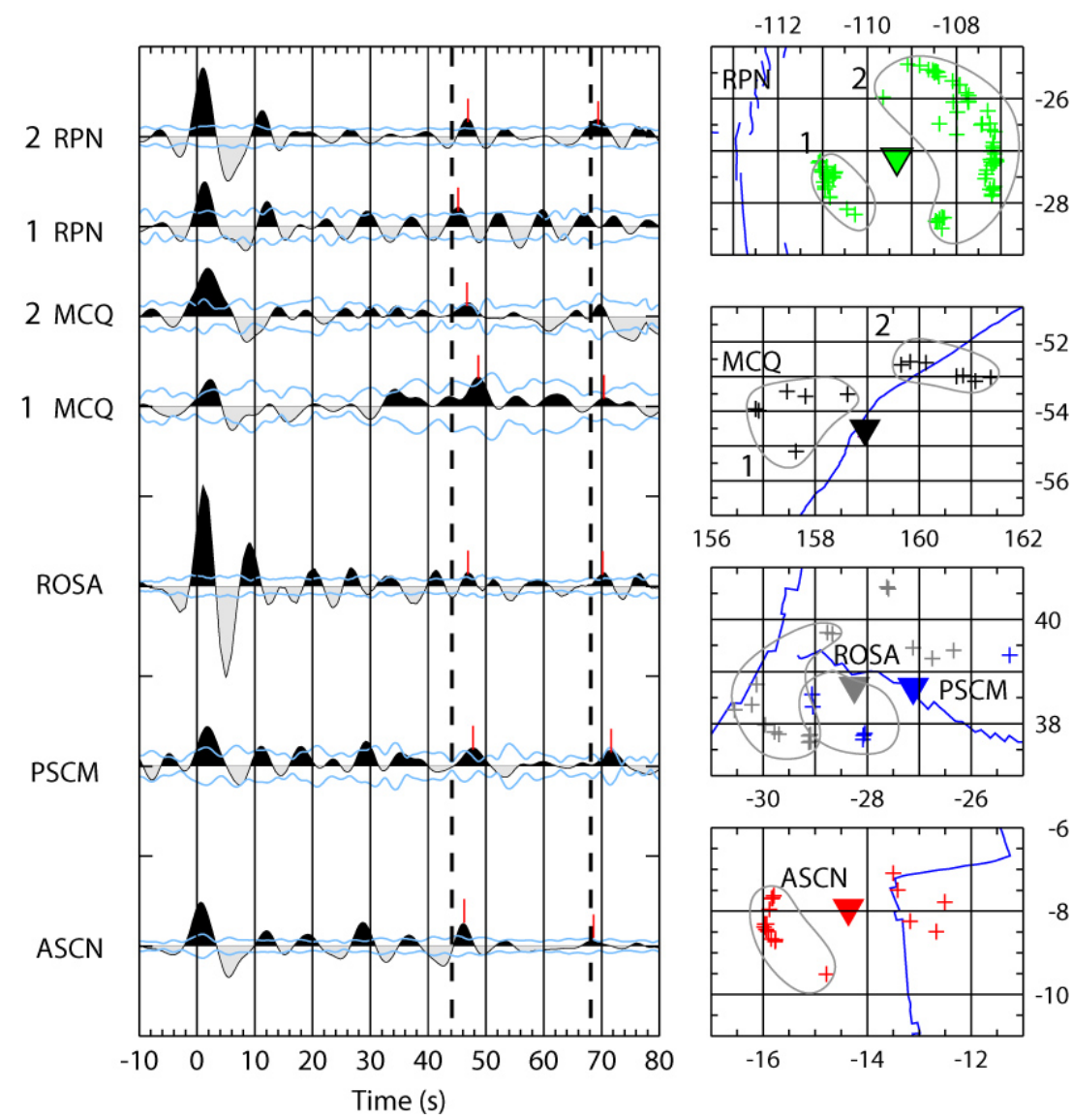

Figure 7. Stacked receiver functions similar to Fig. 2 but shown to deeper depths in order to display the upper mantle discontinuities. The traces are low-pass filtered with corner frequency of $6 \mathrm{~s}$ and moveout corrected to a reference slowness of $6.4 \mathrm{~s} /{ }^{\circ}$ using the IASP91 Earth model prior to stacking. Two bounding blue lines parallel to the mean represent 2 sigma error bounds. The stack traces are based on the geographical locations at a depth of $520 \mathrm{~km}$ for $P$-to- $S$ conversions. We grouped those data that fall near and far away from the mid-oceanic ridge in order to avoid any structural complexities. For the station ASCN we made only one cluster since the data near the ridge are too scant to make a meaningful stack. All stations show clear arrivals of the Ps conversions from the 410 and $660 \mathrm{~km}$ discontinuities (marked by short red lines) and they are delayed with respect to the predicted times from the IASP91 global Earth models (dashed lines).

hand, for the station RPN, the transition zone is thinner on the eastern side of the ridge by $\sim 14 \mathrm{~km}(1.4 \mathrm{~s})$.

\section{Conclusions}

$P$-receiver function analysis at the five stations located near the mid-ocean ridges reveals significant converted energy from the crust-mantle boundary, LAB and an additional deeper low-velocity layer (L). Modeling results reveal that the Moho depths vary from $\sim 10 \mathrm{~km}$ to $\sim 20 \mathrm{~km}$. Hence, we conclude that the crustal thickness beneath the MORs is $\sim 15 \mathrm{~km}$. The LAB depths beneath the MORs vary from $\sim 40 \mathrm{~km}$ to $\sim 65 \mathrm{~km}$. The observed LAB depths are consistent with the thermal cooling model (Stein and Stein, 1992); however, the depth estimates may not represent a pure oceanic plate in view of the contamination from the composition of the ocean islands on which the stations are lo- cated. Further, we observe sufficient converted energy from the upper mantle discontinuities, namely $410 \mathrm{~km}$ and $660 \mathrm{~km}$. These phases are delayed (see Table 1) with respect to the global average. Also, the thickness of the transition zone is found to be small, due to a deepening of the $410 \mathrm{~km}$ and shallowing of the $660 \mathrm{~km}$ discontinuities. This thinning of the transition zone indicates the existence of mantle plumes beneath the stations (e.g., ASCN and RPN). These findings are very much coherent with the fact that the present observations are in close vicinity of the mid-oceanic ridges. However, it must be borne in mind that the data are from the stations located on oceanic islands, and hence the uppermost mantle observations may not be an exact proxy for the true oceanic plate. 
Acknowledgements. Seismic data are from IRIS, DMC. Seismic data analysis was performed in Seismic Handler (K. Stammler). Plots are generated using Generic Mapping Tool (Wessel and Smith, 1995). Xiaohui Yaun (GFZ) provided the moveout script. Thanks to Rainer Kind for his valuable suggestions on the initial version of the manuscript. M. K. Sen, the director of NGRI has kindly permitted the publication of this work. Chinmay Haldar is a $\mathrm{PhD}$ student funded by the University Grants Commission (UGC). This work has been performed under the GENIAS Project PSC0104 (PK) of CSIR-NGRI. We thank the Topical Editor, J. Plomerova, for constructive suggestions and excellent handling of the manuscript. We thank an anonymous reviewer and W. Geissler for their thoughtful and constructive comments and suggestions that improved the original manuscript.

Edited by: J. Plomerova

\section{References}

Agee, C. B.: Phase transformations and seismic structure in the upper mantle and transition zone, in: Ultrahigh-Pressure Mineralogy: Physics And Chemistry of the Earth's Deep Interior, edited by: Hemley, R. J., Reviews in Mineralogy, Mineralogical Society of America, Washington DC, 37, 165-201, 1997.

Atwater, T. and Mudie, J. D.: Block faulting on the Gorda Rise, Science, 159, 729-731, 1968.

Backus, G. E.: Long-wave elastic anisotropy produced by horizontal layering, J. Geophys. Res., 67, 4427-4440, 1962.

Ballard, R. D. and Van Andel, T. H.: Morphology and tectonics of the inner rift valley at lat. $36^{\circ} 50^{\prime} \mathrm{N}$ on the Mid-Atlantic Ridge, Geol. Soc. Am. Bull., 88, 507-530, 1977.

Barclay, A. H. and Toomey, D. R.: Shear wave splitting and crustal anisotropy at the Mid-Atlantic Ridge, $35^{\circ} \mathrm{N}$, J. Geophys. Res, 108, 2378, doi:10.1029/2001JB000918, 2003.

Bina, C. R. and Helffrich, G.: Phase transition Clapeyron slopes and transition zone seismic discontinuity topography, J. Geophys. Res., 99, 15853-15860, 1994.

Bjarnason, I., Menke, W., Flovenz, O., and Caress, D.: Tomographic image of the spreading center in southern Iceland, J. Geophys. Res., 98, 6607-6622, 1993.

Brozena, J. M.: Temporal and spatial variability of sea-floor spreading processes in the northern South-Atlantic, J. Geophys. Res., 91, 497-510, 1986.

Buck, W. R. and Su, W.: Focused mantle upwelling below midocean ridges due to feedback between viscosity and melting, Geophys. Res. Lett., 16, 641-644, 1989.

Burdick, L. J. and Langston, C. A.: Modelling crustal structure through the use of converted phases in teleseismic body wave forms, B. Seismol. Soc. Am., 67, 677-691, 1977.

Christensen, N. I.: Compressional and shear wave velocities in basaltic rocks: Deep Sea Drilling Project, Leg 16, in Initial Reports of the Deep Sea Drilling Project, XVI, 647-650, 1973.

Crawford, W. C., Webb, S. C., and Hildebrand, J. A.: Seafoor compliance observed by long-period pressure and displacement measurements, J. Geophys. Res., 96, 16151-16160, 1991.

Crawford, W. C., Webb, S. C., and Hildebrand, J. A.: Estimating shear velocities in the oceanic crust from compliance measure- ments by two-dimensional finite difference modeling, J. Geophys. Res., 103, 9895-9916, 1998.

Crawford, W. C. and Webb, S. C.: Variations in the distribution of magma in the lower crust and at the Moho beneath the East Pacific Rise at $9^{\circ}-10^{\circ} \mathrm{N}$, Earth Planet. Sci. Lett., 203, 117-130, 2002.

Deuss, A.: Seismic observations of transition zone discontinuities beneath hotspot locations, Geol. Soc. Am., 430, 121-136, 2007.

Du, Z. J. and Foulger, G. R.: The crustal structure beneath the northwest fjords, Iceland, from receiver functions and surface waves, Geophys. J. Int., 139, 419-432, 1999.

Duffy, T. S. and Anderson, D. L.: Seismic velocities in mantle minerals and the mineralogy of the upper mantle, J. Geophys. Res., 94, 1895-1912, 1989.

Duncan, R. A. and Varne, R.: The age and distribution of the igneous rocks of Macquarie Island: Papers and Proceedings of the Royal Society of Tasmania, 122, 45-50, 1988.

Dunn, R. A. and Toomey, D. R.: Seismological evidence for threedimensional melt migration beneath the East Pacific Rise, Nature, 388, 259-262, 1997.

Dunn, R. A. and Forsyth, D. W.: Imaging the transition between the region of mantle melt generation and the crustal magma chamber with short-period Love wave propagation along the southern East Pacific Rise, J. Geophys. Res., 108, 2352, doi:10.1029/2002JB002217, 2003.

Efron, B. and Tibshirani, R.: An Introduction to the Bootstrap, Stanford University, California, USA, 1993.

Evangelidis, C. P., Minshull, T. A., and Henstock, T. J.: Threedimensional crustal structure of Ascension Island from active source seismic tomography, Geophys. J. Int., 159, 311-325, 2004.

Forsyth, D. W.: Geophysical constraints on mantle flow and melt generation beneath mid-ocean ridges, In: mantle flow and melt generation at mid-ocean ridges, edited by: Morgan, J. P., Blackman, D. K., and Sinton, J. M., Geophys. Monogr. Ser., 71, 1-65, AGU, Washington, 1992.

Frederiksen, A. W. and Bostock, M. G.: Modelling teleseismic waves in dipping anisotropic structures, Geophys. J. Int., 141, 401-412, 2000.

Fuchs, K. and Müller, G.: Computation of synthetic seismograms with the reflectivity method and comparison with observations, Geophys. J. R. Astr. Soc., 23, 417-433, 1971.

Gaherty, J. B., Kato, M., and Jordan, T. H.: Seismological structure of the upper mantle: a regional comparison of seismic layering, Phys. Earth Planet. In., 110, 21-41, 1999.

Garmany, J.: Accumulations of melt at the base of young oceanic crust, Nature, 340, 628-632, 1989.

$\mathrm{Gu}$, Y. J. and Dziewonski, A. M.: Global variability of transition zone thickness, J. Geophys. Res., 107, 2135 , doi:10.1029/2001JB000489, 2002.

Gutenberg, B.: Physics of the Earth's Interior, Academic Press, New York, 1959.

Hammond, W. C. and Humphreys, E. D.: Upper mantle seismic wave velocity: Effects of realistic partial melt geometries, J. Geophys. Res., 105, 10975-10986, 2000.

Heit, B., Sodoudi, F., Yuan, X., Bianchi, M., and Kind, R.: An $S$ receiver function analysis of the lithospheric structure in South America, Geophys. Res. Lett., 34, L14307, doi:10.1029/2007GL030317, 2007. 
Helffrich, G.: Topography of the transition zone seismic discontinuities, Rev. Geophys., 38, 141-158, 2000.

Holtzman, B. K.: Melt segregation and strain partitioning: implications for seismic anisotropy and mantle flow, Science, 301, 12271230, 2003.

Holtzman, B. K. and Kohlstedt, D. L.: Stress-driven melt segregation and strain partitioning in partially molten rocks: Effects of stress and strain, J. Petrology, 48, 2379-2406, 2007.

Honkura, Y.: Partial melting and electrical conductivity anomalies beneath the Japan and Philippine seas, Phys. Earth Planet. Inter., 10, 128-134, 1975.

Humphreys, E. D. and K. G.: Dueker, Physicalstate of the western U.S. upper mantle, J. Geophys. Res., 99, 9635-9650, 1994.

Jorg, W. E.: Fassbinder, Easter Island (Chile): Magnetometry of archaeological structures basaltic, J. Org. Geology, 2005.

Kanamori, H. and Press, F.: How thick is the lithosphere?, Nature, 226, 330-331, 1970.

Karato, S.: The role of hydrogen in the electrical conductivity of the upper mantle, Nature, 347, 272-273, 1990.

Katz, R. F., Spiegelman, M., and Holtzman, B.: The dynamics of melt and shear localization in partially molten aggregates, Nature, 442, 676-679, 2006.

Kawakatsu, H., Kumar, P., Takei, Y., Shinohara, M., Kanazawa, T., Araki, E., and Suyehiro, K.: Seismic evidence for sharp lithosphere-asthenosphere boundaries of oceanic plates, Science, 324, 499-502, 2009.

Kelemen, P. B., Hirth, G., Shimizu, N., Spiegelman, M., and Dick, H. J.: A review of melt migration processes in the adiabatically upwelling mantle beneath oceanic spreading ridges, Phil. Trans. Roy. Soc. Lond., A, 355, 1-35, 1997.

Kendall, J. M.: Teleseismic arrivals at a mid-ocean ridge: effects of mantle melt and anisotropy, Geophys. Res. Lett., 21, 301-304, 1994.

Kind, R.: The reflectivity method for a buried source, J. Geophys., 44, 511-523, 1978.

Kind, R., Yuan, X., and Kumar, P.: Seismic receiver functions and lithosphere-asthenosphere Boundary, Tectonophysics, 536, 2543, 2012.

Kumar, P. and Kawakatsu, H.: Imaging the seismic lithosphereasthenosphere boundary of the oceanic plate, Geochem. Geophys. Geosyst., 12, Q01006, doi:10.1029/2010GC003358, 2011.

Kumar, P., Kawakatsu, H., Shinohara, M., Kanazawa, T., Araki, E., and Suyehiro, K.: $\mathrm{P}$ and $\mathrm{S}$ receiver function analysis of seafloor borehole broadband seismic data, J. Geophys. Res., 116, B12308, doi:10.1029/2011JB008506, 2011.

Langmuir, J., Klein, E. M., and Plank, T.: in Mantle Flow and Melt Generation at Mid-Ocean Ridges:American Geophysical Union, Washington, DC, 183-200, 1992.

Langston, C. A.: Corvallis, Oregon, crustal and upper mantle structure from teleseismic P and S waves, B. Seismol. Soc. Am., 67, 713-724, 1977.

Leeds, A. R.: Lithospheric thickness in the western Pacific, Phys. Earth Planet. In., 11, 61-64, 1975.

Li, X., Kind, R., and Yuan, X.: Seismic study of upper mantle and transition zone beneath hotspots, Phys. Earth Planet Int., 136, 79-92, 2003.

Menke, W., Brandsdottir, B., Jakobsdottir, S., and Stefansson, R.: Seismic anisotropy in the crust at the Mid-Atlantic plate boundary in south-west Iceland, Geophys. J. Int., 119, 783-790, 1994.
Mierdel, K., Keppler, H., Smyth, J. R., and Langenhorst, F.: Water Solubility in Aluminous Orthopyroxene and underline Science and the Origin of Earth's Asthenosphere, Science, 315, 364-368, 2007.

Montagner, J. P. and Ritsema, J.: Interactions between ridges and plumes, Science, 294, 1472-1473, 2001.

Nettles, M. and Dziewo'nski, A.: Radially anisotropic shear velocity structure of the upper mantle globally and beneath North America, J. Geophys. Res.-Sol. Ea., 113, B02303, doi:10.1029/2006JB004819, 2008.

Nowacki, A., Kendall, J. M., and Wookey, J.: Mantle anisotropy beneath the Earth's mid-ocean ridges, Earth Planet. Sc. Lett., 317318, 56-67, 2012.

Parsons, B. and Sclater, J. G.: An analysis of the variation of ocean floor bathymetry and heat flow with age, J. Geophys. Res., 82, 803-827, 1977.

Phipps Morgan, J.: Melt migration beneath mid-ocean spreading centers, Geophys. Res. Lett., 145, 1238-1241, 1987.

Revenaugh, J. and Jordan, T. H.: Mantle layering from reverberations: 2. The transition zone, J. Geophys. Res., 96, 19763-19780, 1991.

Rodgers, A. and Harben, P.: Modeling the Conversion of Hydroacoustic to Seismic Energy at Islands and Continental Margins: Preliminary Analysis of Ascension Island Data, 21st Seismic Research Symposium, Technologies for Monitoring the Comprehensive Nuclear-Test-Ban Treaty Las Vegas, Nevada, 1999.

Rychert, C. A. and Shearer, P. M.: A global view of the lithosphereasthenosphere boundary: Science, 324, 495-498, 2009.

Rychert, C. A. and Shearer, P. M.: Imaging the lithosphereasthenosphere boundary beneath the Pacific using SS waveform modeling, J. Geophys. Res., 116, B07307, doi:10.1029/2010JB008070, 2011.

Schmerr, N.: The Gutenberg discontinuity: melt at the lithosphereasthenosphere boundary, Science, 335, 1480-1483, 2012.

Shankland, T. J. and Waff, H. S.: Partial melting and electrical conductivity anomalies in the upper mantle, J. Geophys. Res., 82, 5409-5417, 1977.

Shearer, P. M.: Upper Mantle Seismic Discontinuities, American Geophysical Union, 115-131, 2000.

Shinohara, M., Fukano, T., Kanazawa, T., Araki, E., Suyehiro, K., Mochizuki, M., Nakahigashi, K., Yamada, T., and Mochizuki, K.: Upper mantle and crustal seismic structure beneath the Northwestern Pacific Basin using seafloor borehole broadband seismometer and ocean bottom seismometers, Phys. Earth Planet. In., 170, 95-106, 2008.

Sinton, J. M. and Detrick, R. S.: Mid-Ocean Ridge Magma Chambers, J. Geophys. Res., 97, 197-216, 1992.

Sobolev, S. V., Zeyen, H., Stoll, G., Werling, F., R. Althern, and K. Fuchs, Upper mantle temperatures from teleseismic tomography of French Massif Central including effects of composition, mineral reactions, anharmonicity, anelasticity and partial melt. Earth Planet. Sci. Left., v. 139, p. 147-163, 1996.

Sparks, D. W., Parmentier, E. M., and Morgan, J. P.: ThreeDimensional Mantle Convection Beneath a Segmented Spreading Center: Implications for Along-Axis Variations in Crustal Thickness and Gravity, J. Geophys. Res., 98, 21977-21995, 1993. 
Spiegelman, M. and McKenzie, D.: Simple 2-D models for melt extraction at mid-ocean ridges and island arcs, Earth Planet. Sci. Lett., 83, 137-152, 1987.

Stammler, K.: Seismic Handler: programmable multichannel data handler for interactive and automatic processing of seismological analysis: Comput. Geosci., 19, 135-140, 1993.

Stein, C. A. and Stein, S.: A model for the global variation in oceanic depth and heat flow with lithospheric age, Nature, 359, 123-129, 1992.

Tan, Y. and Helmberger, D. V.: Trans-Pacific upper mantle shear velocity structure, J. Geophys. Res., 112, B08301, doi:10.1029/2006JB004853, 2007.

Tapley, I., Dijkstra, A. H., and Brolsma, H.: The Geology, Landforms and Topography of Sub-Antarctic Macquarie Island, Australia, as revealed by AIRSAR, Geosci. Remote Sens. Symposium, 1, 2004.

Toomey, D. R., Purdy, G. M., Solomon, S. C., and Wilcock, W. S. D.: The three-dimensional seismic velocity structure of the East Pacific Rise, near latitude 9³0’ N, Nature, 347, 639-645, 1990.

Utada, H. and Baba, K.: Estimating the electrical conductivity of the melt phase of a partially molten asthenosphere from seafloor magnetotelluric sounding data, Phys. Earth Planet. Int., doi:10.1016/j.pepi.2013.12.004, 2013.
Vinnik, L. P.: Detection of waves converted from $\mathrm{P}$ to $\mathrm{SV}$ in the mantle, Phys. Earth Planet. In., 15, 294-303, 1977.

White, R. S., McKenzie, D., and Onions, R. K.: Oceanic crustal thickness from seismic measurements and rare earth element inversions, J. Geophys. Res., 97, 19683-19715, 1992.

Xu, Y. and Wiens, D. A.: Upper mantle structure of the southwest Pacific from regional waveform inversion, J. Geophys.Res., 102, 27439-27451, 1997.

Yaun, X., Ni, J., Kind, R., Mechie, J., and Sandvol, E.: Lithospheric and upper mantle structure of southern Tibet from a seismological passive source experiment, J. Geophys. Res., 102, 2749127500, 1977.

Zhang, Y. and Tanimoto, T.: High resolution global upper mantle structure and plate tectonics, J. Geophys. Res, 98, 148-227, 1993.

Zhao, D., Hasegawa, A., and Horiuchi, S.: Tomographic imaging of $\mathrm{P}$ and $\mathrm{S}$ wave velocity structure beneath northeastern Japan, J. Geophys. Res., 97, 19909-19928, 1992. 